\title{
Antiarrhythmic Effects of Ranolazine in Canine Pulmonary Vein Sleeve Preparations
}

\author{
Serge Sicouri, MD, \\ Masonic Medical Research Laboratory, Utica, NY \\ Aaron Glass, BS, \\ Masonic Medical Research Laboratory, Utica, NY \\ Luiz Belardinelli, MD, and \\ CV Therapeutics, Palo Alto, CA \\ Charles Antzelevitch, PhD, FHRS \\ Masonic Medical Research Laboratory, Utica, NY
}

\begin{abstract}
Objectives-To determine the electrophysiologic effects of ranolazine in canine pulmonary veins (PV) sleeve preparations.
\end{abstract}

Background-Ectopic activity arising from the PV plays a prominent role in the development of atrial fibrillation (AF).

Methods-Transmembrane action potentials were recorded from canine superfused left superior or inferior PV sleeves using standard microelectrode techniques. Acetylcholine (ACh, $1 \mu \mathrm{M})$, isoproterenol $(1 \mu \mathrm{M})$, high calcium $\left(\left[\mathrm{Ca}^{2+}\right]_{0}=5.4 \mathrm{mM}\right)$ or a combination was used to induce early or delayed afterdepolarizations (EADs or DADs) and triggered activity.

Results-Ranolazine $(10 \mu \mathrm{M})$ significantly accentuated use-dependent depression of maximal rate of rise of action potential upstroke $\left(\mathrm{V}_{\max }\right)$. Reducing basic cycle length (BCL) from 2000 to $200 \mathrm{~ms}$ resulted in a decrease of $\mathrm{V}_{\max }$ from $279 \pm 58$ to $146 \pm 23 \mathrm{~V} / \mathrm{s}$ (47.7\%) in control and from $241 \pm 71$ to $72 \pm 63 \mathrm{~V} / \mathrm{s}(70.2 \%)$ following $10 \mu \mathrm{M}$ ranolazine $(\mathrm{n}=4, \mathrm{p}<0.05)$. Ranolazine slightly abbreviated action potential duration, but induced significant rate-dependent prolongation of effective refractory period due to development of post-repolarization refractoriness ( $n=6, p<0.05)$. Ranolazine $(10 \mu \mathrm{M})$ caused loss of excitability resulting in 2:1 activation failure at BCLs $\leq 200 \mathrm{~ms}(\mathrm{n}=3)$ and suppressed late phase 3 EADs, DADs and triggered activity elicited by exposure of the PV sleeves to Ach +isoproterenol, or high $\left[\mathrm{Ca}^{2+}\right]_{0}+$ rapid pacing $(\mathrm{n}=11)$.

Conclusions-Ranolazine causes marked use-dependent inhibition of sodium channel activity leading to prolongation of effective refractory period, conduction slowing and block as well as

\footnotetext{
Address for editorial correspondence: Serge Sicouri, MD, Masonic Medical Research Laboratory, 2150 Bleecker Street, Utica, New York, U.S.A. 13501-1787, Phone: (315) 735-2217, FAX: (315) 735-5648, E-mail: sicouris@ mmrl.edu.

Address for reprints: Serge Sicouri, MD, E-mail: sicouris@ mmrl.edu And Charles Antzelevitch, PhD, FACC, FAHA, FHRS, Executive Director and Director of Research, Gordon K. Moe Scholar, Masonic Medical Research Laboratory, 2150 Bleecker Street, Utica, N.Y. 13501, Phone: (315)735-2217, FAX: (315)735-5648, E-mail: ca@mmrl.edu

Publisher's Disclaimer: This is a PDF file of an unedited manuscript that has been accepted for publication. As a service to our customers we are providing this early version of the manuscript. The manuscript will undergo copyediting, typesetting, and review of the resulting proof before it is published in its final citable form. Please note that during the production process errors may be discovered which could affect the content, and all legal disclaimers that apply to the journal pertain.

Conflict of interest: Dr. Antzelevitch received research support and is a consultant to CV Therapeutics. Dr Belardinelli is an employee of CV Therapeutics.
} 
suppression of late phase 3 EAD and DAD-mediated triggered activity in canine PV sleeves. Our data suggest that ranolazine may be useful in suppressing AF triggers arising from the PV sleeves.

\section{Keywords}

Atrial fibrillation; Antiarrhythmic drugs; Sodium channel blocker; Electrophysiology; Pharmacology

\section{INTRODUCTION}

In the clinic, drug therapy with antiarrhythmic agents as well as catheter ablation techniques are the main tools used for suppression of atrial arrhythmias, including atrial fibrillation (AF). ${ }^{1}$ Ectopic activity arising from the pulmonary veins (PV) has been shown to play a prominent role in the development of $\mathrm{AF}^{2}$ Pulmonary vein isolation is a procedure used frequently to eliminate the triggers arising from the pulmonary veins. Late phase 3 early afterdepolarizations (EADs) as well as delayed afterdepolarization (DAD)-induced triggered activity, originating from PV sleeves following parasympathetic and/or sympathetic stimulation, have been proposed as potential triggers in the initiation of AF. ${ }^{3-7}$.

Ranolazine is an anti-anginal agent shown to possess antiarrhythmic activity in atrial and ventricular experimental models $8-10$ as well as in patients with non-ST segment elevation acute coronary syndrome. 11,12 The action of ranolazine to suppress ventricular arrhythmias is attributed to its inhibition of late sodium channel current (INa), whereas its action to suppress AF is thought to be largely due to its ability to inhibit the rapidly activating delayed rectifier potassium current (IKr) as well as its ability to produce potent use-dependent inhibition of peak INa. The present study was designed to determine the effects of ranolazine on electrical activity recorded from canine PV sleeve preparations and to evaluate its antiarrhythmic potential in atrial arrhythmias, particularly AF.

\section{METHODS}

This investigation conforms to the Guide for Care and Use of Laboratory Animals published by the National Institutes of Health (NIH publication No 85-23, Revised 1996) and was approved by the ACUC of the Masonic Medical Research Laboratory.

Adult mongrel dogs weighing 20-35 kg were anticoagulated with heparin (180 IU/kg) and anesthetized with sodium pentobarbital $(35 \mathrm{mg} / \mathrm{kg}$, IV). The chest was opened via a leftthoracotomy and the heart excised and placed in a cold cardioplegic solution $\left(\left[\mathrm{K}^{+}\right]_{0}=8 \mathrm{mmol} /\right.$ $\left.\mathrm{L}, 4^{\circ} \mathrm{C}\right)$.

\section{Superfused pulmonary vein sleeve preparation}

PV sleeve preparations (approximately $2.0 \times 1.5 \mathrm{~cm}$ ) were isolated from left canine atria. The thickness of the preparation was approximately $2 \mathrm{~mm}$. Left superior pulmonary veins were used preferentially in most experiments. The preparations were placed in a small tissue bath and superfused with Tyrode's solution of the following composition (mM): $129 \mathrm{NaCl}, 4 \mathrm{KCl}$, $0.9 \mathrm{NaH}_{2} \mathrm{PO}_{4}, 20 \mathrm{NaHCO}_{3}, 1.8 \mathrm{CaCl}_{2}, 0.5 \mathrm{MgSO}_{4}, 5.5$ glucose, buffered with $95 \% \mathrm{O}_{2} / 5 \%$ $\mathrm{CO}_{2}\left(35 \pm 0.5^{\circ} \mathrm{C}\right)$. $\mathrm{PV}$ preparations were stimulated at a basic cycle length (BCL) of $1000 \mathrm{~ms}$ during the equilibration period (1h) using electrical stimulation (1-3 ms duration, 2.5 times diastolic threshold intensity) delivered through silver bipolar electrodes insulated except at the tips. Transmembrane potentials were recorded using glass microelectrodes filled with $3 \mathrm{M} \mathrm{KCl}$ (10-20 M $\Omega$ DC resistance) connected to a high input-impedance amplification system (World Precision Instruments, model KS-700, New Haven, CT). The following parameters were measured: take-off potential, action potential amplitude (APA), action potential duration at 50 
and $85 \%$ repolarization $\left(\mathrm{APD}_{50}\right.$ and $\left.\mathrm{APD}_{85}\right)$ and maximal rate of rise of action potential upstroke $\left(\mathrm{V}_{\max }\right)$. Transmembrane action potentials were recorded at a sampling rate of $41 \mathrm{kHz}$. Take-off potential measurement was used instead of resting membrane potential because of the slow phase 3 of the action potential of the PV sleeve preparation which fails to return to the resting potential at the fastest rates. The effective refractory period was measured by introducing single extrastimuli following a train of 10 beats at basic cycle lengths (BCLs) of 1000,500 , and $300 \mathrm{~ms}$. ERP was defined as the shortest S1-S2 interval capable of eliciting a propagated response.

Drugs-Ranolazine (CV Therapeutics, Palo Alto, CA) was dissolved in distilled water to form a stock solution of $10 \mathrm{mM}$ and used at a final concentration of 10 to $20 \mu \mathrm{M}$. Isoproterenol (Sigma-Aldrich Corp.St. Louis, MO) was dissolved in distilled water to form a stock solution of $1 \mathrm{mM}$ and used at a final concentration of $1 \mu \mathrm{M}$. Acetylcholine (ACh) was dissolved in distilled water to form a stock solution of $10 \mathrm{mM}$ and used at a concentration of $1 \mu \mathrm{M}$.

Statistics-Statistical analysis was performed using one way repeated measures analysis of variance (ANOVA) followed by Bonferoni's test. Mean values were considered to be different at $\mathrm{p}<0.05$.

\section{RESULTS \\ Control experiments}

In four experiments we tested the viability of the PV sleeve preparation by recording electrical activity over a period of 4 hours of superfusion with normal Tyrode's solution. APD and Vmax remained largely unchanged over a 4 hour period of exposure to normal Tyrode's solution. No spontaneous electrical activity was recorded from any of the preparations.

\section{Effects of ranolazine on pulmonary vein (PV) sleeve preparations}

Illustrated in Fig. 1 is a representative example of the rate-dependent effects of ranolazine on the action potential of a PV sleeve preparation (panel A and B). Ranolazine induced a marked decrease in $\mathrm{V}_{\max }$ and a slight depolarization of take-off potential in the PV sleeve preparation. This effect was more accentuated at fast stimulation rates. Composite data of the rate-dependent effects of ranolazine on $\mathrm{V}_{\max }$ and take-off potential recorded under steady-state conditions in $4 \mathrm{PV}$ sleeve preparations are shown in panel C and D. Ranolazine $(10 \mu \mathrm{M}, 30 \mathrm{~min})$ significantly accentuated the use-dependent depression of $\mathrm{V}_{\max }$ and take-off potential $(\mathrm{n}=4, \mathrm{p}<0.05)$. Fig. 2 shows the effects of ranolazine $(10 \mu \mathrm{M})$ on $\mathrm{V}_{\max }$ following an abrupt change in basic cycle length (BCL) from 2000 to $200 \mathrm{~ms}$ in panels A and B and from 2000 to $170 \mathrm{~ms}$ in panels C and $\mathrm{D}$. Ranolazine accentuated the development of use-dependent depression of $\mathrm{V}_{\max }$. The increase in stimulation rate led to a decrease of $\mathrm{V}_{\max }$ from $279 \pm 58$ to $146 \pm 23 \mathrm{~V} / \mathrm{s}(47.7 \%$ decrease) under control conditions and from $241 \pm 71$ to $72 \pm 63 \mathrm{~V} / \mathrm{s}$ ( $70.2 \%$ decrease) following ranolazine $(\mathrm{n}=4, \mathrm{p}<0.05)$.

\section{Effects of ranolazine on action potential duration $\left(A P D_{85}\right)$ and effective refractory period}

In another series of experiments we determined the effects of ranolazine on action potential duration and effective refractory period. As illustrated in Fig. 3. Ranolazine $(10 \mu \mathrm{M})$ induced a rate-dependent abbreviation of $\mathrm{APD}_{85}$, but a rate-dependent increase in ERP due to the development of post-repolarization refractoriness (the difference between effective refractory period and $\mathrm{APD}_{85}$ ) in $\mathrm{PV}$; effective refractory period corresponds to $\mathrm{APD}_{85}$ under control conditions but is significantly increased following exposure to ranolazine, particularly at fast rates $\left(\mathrm{BCL}=500\right.$ and $300 \mathrm{~ms} ; \mathrm{n}=6, \mathrm{p}<0.05$ for $\mathrm{ERP}$ vs $\left.\mathrm{APD}_{85}\right)$. 


\section{Effects of ranolazine on conduction}

In another series of experiments, we determined the changes in conduction velocity induced by ranolazine. Conduction velocity was measured between two microelectrodes placed along the PV sleeve. Ranolazine accentuated the slowing of conduction caused by an increase in stimulation rate. Reducing BCL from 2000 to $300 \mathrm{~ms}$ increased impulse conduction time from $6.6 \pm 1.3$ to $8.5 \pm 1.9 \mathrm{~ms}(30.7 \%$ increase) in controls and from $7.7 \pm 1$ to $12.6 \pm 3.4 \mathrm{~ms}(65.7 \%$ increase) after ranolazine ( $\mathrm{n}=4, \mathrm{p}<0.05)$. Pacing at BCLs $\leq 200 \mathrm{~ms}$ led to loss of excitability, resulting in 2:1 activation failure in the presence of ranolazine. Fig. 4 illustrates an example of the effect of ranolazine $(10 \mu \mathrm{M})$ to induce $2: 1$ conduction block. The two simultaneous recordings (AP1 and AP2) shown in Fig. 4 were separated by $16 \mathrm{~mm}$. One to one conduction, observed at a BCL of $170 \mathrm{~ms}$ (first 6 beats), was converted to 2:1 conduction at a BCL of 150 ms.

\section{Effects of ranolazine on early and delayed afterdepolarizations-induced triggered activity}

In another series of experiments, we determined the effects of ranolazine on delayed afterdepolarizations (DADs), late phase 3 early afterdepolarizations (EADs) and triggered activity elicited by exposure of the PV sleeve preparations to acetylcholine (ACh) and isoproterenol, or high $\left[\mathrm{Ca}^{2+}\right]_{\mathrm{o}}$ and rapid pacing $(\mathrm{BCL}=150$ to $70 \mathrm{~ms})$. In the example illustrated in Fig. 5, ranolazine $(10 \mu \mathrm{M})$ abolished rate-dependent DADs and DAD-induced triggered activity induced by isoproterenol. Similar results were obtained in 3 of 3 preparations. Ranolazine also markedly reduced DAD amplitude or suppressed DAD activity induced by a combination of $\mathrm{ACh}$ and high calcium $\left(\left[\mathrm{Ca}^{2+}\right]_{\mathrm{o}}=5.4 \mathrm{mM}\right)(\mathrm{n}=4$; Fig. 6). Table 1 summarizes the maximum amplitude and coupling interval of DADs recorded under these various conditions and the concentrations of ranolazine needed to suppress DAD activity. Ranolazine, at concentrations of 10 to $20 \mu \mathrm{M}$ completely eliminated DAD activity in the PV sleeve preparations.

Late phase 3 EADs and EAD-induced triggered activity recorded at slower rates of stimulation following exposure of the PV sleeve preparations to ACh $(1 \mu \mathrm{M})$ alone or combined with isoproterenol or high calcium $\left(\left[\mathrm{Ca}^{2+}\right]_{\mathrm{O}}=5.4 \mathrm{mM}\right)$ were also suppressed by ranolazine $(10 \mathrm{uM})$ in 3 of 3 preparations (Fig. 7).

\section{DISCUSSION}

$\mathrm{AF}$ is the most common arrhythmia requiring medical attention. Ectopic activity arising from the PV sleeves is thought to be an important source of triggers and in some cases substrate for the development of AF $13-15$. Over the last decade, radiofrequency ablation has become the treatment of choice for drug resistant AF. Segmental PV isolation and circumferential PV ablation are surgical procedures now commonly used to suppress refractory atrial arrhythmias including AF. ${ }^{16}$

The results of the present study indicate that concentrations of ranolazine within the therapeutic range $(2-10 \mu \mathrm{M})$ are capable of inducing rate-dependent depression of $\mathrm{V}_{\max }$ and excitability as well as rate-dependent increase in effective refractory period due to development of postrepolarization refractoriness, a slowing of conduction and activation failure at rapid rates of stimulation. Our results also indicate that ranolazine suppresses DADs, late phase 3 EADs, and triggered activity arising via these mechanisms. It is noteworthy a rate-dependent decrease in $\mathrm{V}_{\text {max }}$ is present under control conditions and is a typical feature of PV sleeve preparations as well as arterially-perfused atrial preparation; this is due largely to the progressive decrease in take-off potential at faster rates of stimulation. 
The effects of ranolazine in PV sleeves preparations to depress sodium channel activity, reduce excitability, increase conduction time and to induce conduction block are similar to those recently reported for the effects of the drug in canine atrial tissues. ${ }^{10}$ In the coronary-perfused isolated right atrium, ranolazine produced a marked use-dependent depression of sodium channel parameters including $\mathrm{V}_{\max }$, conduction velocity, and diastolic threshold of excitation and induced post-repolarization refractoriness in the atria. ${ }^{10}$

\section{EAD and DAD-induced triggered activity in PV sleeves}

The present study shows that late phase 3 EADs and DADs can be easily induced in PV sleeve preparations following the addition of isoproterenol, $\mathrm{ACh}$, high calcium alone or their combination. Similar findings were previously reported by Chen and co-workers in canine and rabbit isolated single PV myocytes, ${ }^{17}, 18$ by Patterson and co-workers in isolated canine pulmonary vein sleeve preparations, 4,5 and by Burashnikov and co-workers in coronaryperfused right atrial preparations ${ }^{3,}$, 19 . In isolated myocytes, isoproterenol was shown to increase automaticity and induce spontaneous as well as EAD or DAD-induced triggered activity. ${ }^{17,18}$ First characterized by Burashnikov and Antzelevitch, 3,19 late-phase 3 EADs and late-phase 3 EAD-induced triggered activity is a new concept of arrhythmogenesis. Abbreviated repolarization permits normal sarcoplasmic reticulum calcium release and associated sodium-calcium exchange inward current to induce a late phase $3 \mathrm{EAD}$, resulting in closely coupled trigged responses when it reaches threshold. Conditions permitting intracellular calcium loading facilitate the development of late phase 3 EADs. Patterson et al. showed that autonomic stimulation could give rise to this phenomenon in canine PV sleeves and in some cases result in a run of triggered responses. 4,5

\section{Ionic mechanisms}

In isolated canine ventricular myocytes, ranolazine has been shown to inhibit the late sodium $\left(\mathrm{IC}_{50}=6 \mu \mathrm{mol} / \mathrm{L}\right)$, rapidly activating delayed rectifier potassium $\left(\mathrm{I}_{\mathrm{Kr}}, \mathrm{IC}_{50}=12 \mu \mathrm{mol} / \mathrm{L}\right)$ and late L-type calcium (late $\mathrm{I}_{\mathrm{Ca}}, \mathrm{IC}_{50}=50 \mu \mathrm{mol} / \mathrm{L}$ ) currents. ${ }^{8}$ Other potassium $\left(\mathrm{I}_{\mathrm{Ks}}, \mathrm{I}_{\mathrm{to}}, \mathrm{I}_{\mathrm{K} 1}\right.$ ) and calcium (peak $\mathrm{I}_{\mathrm{Ca}}$ ), as well as $\mathrm{Na} / \mathrm{Ca}$ exchanger, currents are not affected by ranolazine or are only reduced at much higher concentrations that are beyond the therapeutic range of the drug $(2-10 \mu \mathrm{mol} / \mathrm{L}) .{ }^{8}$ Previous studies have also shown that ranolazine blocks $\mathrm{I}_{\mathrm{Na}}$ with $\mathrm{IC}_{50}$ of 294 $\mu \mathrm{mol} / \mathrm{L}$ in canine ventricular myocytes $\left(\right.$ at $0.1 \mathrm{~Hz}$ ) ${ }^{20}$ and reduces $\mathrm{V}_{\max }$ with an $\mathrm{IC}_{50}$ of $>100$ $\mu \mathrm{mol} / \mathrm{L}$ in Purkinje fibers and $\mathrm{M}$ cell preparations paced at a BCL of $500 \mathrm{~ms} .8,9$

In marked contrast to the lack of an effect of ranolazine at therapeutic concentrations on peak $\mathrm{I}_{\mathrm{Na}}$ in ventricular myocardium and Purkinje fibers, the drug has recently been shown to exert potent use-dependent block of peak $\mathrm{I}_{\mathrm{Na}}$ (estimated from depression of $\mathrm{V}_{\max }$ ) in canine atrial tissues. The atrial selective-effects of ranolazine to depress peak $\mathrm{I}_{\mathrm{Na}}$ and associated parameters, such as impulse conduction velocity, excitability, and post-repolarization refractoriness $21-$ 23 , were shown to result from a more negative steady-state inactivation relationship for $\mathrm{I}_{\mathrm{Na}}$ in atrial than ventricular cells. A slow phase 3 repolarization in atrial cells further potentiates the effect of ranolazine at rapid activation rates by abolishing the diastolic interval and preventing full repolarization, which leads to a more positive take-off potential for the next beat and reduced availability of sodium channels.

Another factor that contributes to the reduced availability of peak $\mathrm{I}_{\mathrm{Na}}$ in atria is the more depolarized resting membrane potential of atrial vs. ventricular cells. Intrinsic atrio-ventricular differences in the resting membrane potential slope of late repolarization are largely explained by a smaller $\mathrm{I}_{\mathrm{K} 1}$ in atrial vs. ventricular cells. ${ }^{24}$ 
The present study shows that the atrioventricular differences in the response of peak $\mathrm{I}_{\mathrm{Na}}$ to ranolazine applies to the pulmonary vein sleeves as well, and that $\mathrm{I}_{\mathrm{Na}}$ inhibition is potent at concentrations of the drug within the therapeutic range.

The effect of ranolazine to suppress DAD and late phase 3 EAD activity is best explained by its actions to reduce intracellular calcium loading secondary to its effects to inhibit $\mathrm{I}_{\mathrm{Na}}$ and late $\mathrm{I}_{\mathrm{Ca}}$, as well as its weak action to inhibit $\beta$ adrenergic receptors. $9,25,26$

\section{Clinical implications: antiarrhythmic effects of ranolazine}

Most antiarrhythmic agents shown to be effective in terminating and/or preventing clinical AF or atrial flutter act primarily by reducing sodium channel current, $\mathrm{I}_{\mathrm{Na}}$ (e.g., propafenone or flecainide) or delayed rectifier current, $\mathrm{I}_{\mathrm{Kr}}$ (e.g., dofetilide) or by blocking multiple channels $\left(\mathrm{I}_{\mathrm{to}}, \mathrm{I}_{\mathrm{Kr}}, \mathrm{I}_{\mathrm{Ks}}, \mathrm{I}_{\mathrm{Ca}}, \mathrm{I}_{\mathrm{Na}}\right.$, amiodarone). Use of these agents is limited by their potential ventricular pro-arrhythmic actions and/or organ toxicity at therapeutically effective doses. ${ }^{9}, 27,28$

A number of clinical ${ }^{29}$ and experimental studies have suggested a prominent role of pulmonary veins in the genesis of atrial arrhythmias, including $\mathrm{AF}^{2}, 18$. Ranolazine is a novel antianginal agent with relatively mild adverse effects and no known proarrhythmic effects. ${ }^{30}$ Previous studies have demonstrated its effect to suppress arrhythmias associated with acquired and congenital long QT syndrome. $8,9,31$ Our results indicate that, in canine PV sleeves preparations ranolazine, at therapeutic concentrations, produce a marked use-dependent inhibition of sodium channel activity leading to post-repolarization refractoriness, conduction slowing and block as well as suppression of late phase 3 EAD and DAD-related triggered activity. Significant prolongation of refractory period may increase the wave length (WL $=$ refractory period $\times$ conduction velocity) of reentrant circuits ${ }^{29}$. These data suggest that ranolazine may be useful in suppressing the triggers and perhaps also the substrate arising from PV sleeves that contribute to the development of atrial fibrillation. The actions of ranolazine to produce potent block of the sodium channels in the atria are similar to those of other Class IC antiarrhythmic agents such as propafenone and flecainide. However, ranolazine's unique ion channel profile, exhibiting atrial selectivity in its action to suppress peak $\mathrm{I}_{\mathrm{Na}}$, avoids the adverse pro-arrhythmic ventricular action of these other agents. ${ }^{10}$

Although clinical trials specifically designed to assess the actions of ranolazine to suppress AF are not available, it is noteworthy that the recently published results of the MERLIN trial indicate that the drug exerts both ventricular and supraventricular antiarrhythmic activity. Treatment with ranolazine resulted in significantly lower incidences of ventricular tachycardia lasting $\geq 8$ beats ( $5.3 \%$ vs $8.3 \%$; $\mathrm{p}<0.001)$, supraventricular tachycardia ( $44.7 \%$ vs $55.0 \%$; $\mathrm{p}$ $<0.001)$, or new-onset atrial fibrillation $(1.7 \%$ vs $2.4 \% ; \mathrm{p}=0.08) .{ }^{12}$ The results of the present study, coupled with those from our recent study demonstrating the atrial-selective electrophysiological (anti-fibrillatory) effects of ranolazine, ${ }^{10}$ warrant further investigation of the potential of ranolazine to suppress AF.

\section{Acknowledgements}

Supported by grant HL47678 from NHLBI (CA) and NYS and Florida Grand Lodges F. \& A.M.

\section{References}

1. Fuster V. Atrial fibrillation: an epidemiologic, scientific and clinical challenge. Nat Clin Pract Cardiovasc Med 2005;2:225. [PubMed: 16265487]

2. Haissaguerre M, Jais $P$, Shah DC, et al. Spontaneous initiation of atrial fibrillation by ectopic beats originating in the pulmonary veins. N Engl J Med 1998;339:659-666. [PubMed: 9725923]

3. Burashnikov A, Antzelevitch C. Late-Phase 3 EAD. A Unique Mechanism Contributing to Initiation of Atrial Fibrillation. PACE 2006;29:290-295. [PubMed: 16606397] 
4. Patterson E, Po SS, Scherlag BJ, et al. Triggered firing in pulmonary veins initiated by in vitro autonomic nerve stimulation. Heart Rhythm 2005;2:624-631. [PubMed: 15922271]

5. Patterson E, Lazzara R, Szabo B, et al. Sodium-calcium exchange initiated by the Ca2+ transient: an arrhythmia trigger within pulmonary veins. J Am Coll Cardiol 2006;47:1196-1206. [PubMed: 16545652]

6. Wongcharoen W, Chen YC, Chen YJ, et al. Aging increases pulmonary veins arrhythmogenesis and susceptibility to calcium regulation agents. Heart Rhythm 2007;4:1338-1349. [PubMed: 17905341]

7. Lo LW, Chen YC, Chen YJ, et al. Calmodulin kinase II inhibition prevents arrhythmic activity induced by alpha and beta adrenergic agonists in rabbit pulmonary veins. Eur J Pharmacol 2007;571:197-208. [PubMed: 17612522]

8. Antzelevitch C, Belardinelli L, Zygmunt AC, et al. Electrophysiologic effects of ranolazine: a novel anti-anginal agent with antiarrhythmic properties. Circulation 2004;110:904-910. [PubMed: 15302796]

9. Antzelevitch C, Belardinelli L, Wu L, et al. Electrophysiologic properties and antiarrhythmic actions of a novel anti-anginal agent. J Cardiovasc Pharmacol Therapeut 2004;9:S65-S83.

10. Burashnikov A, Di Diego JM, Zygmunt AC, et al. Atrium-selective sodium channel block as a strategy for suppression of atrial fibrillation: differences in sodium channel inactivation between atria and ventricles and the role of ranolazine. Circulation 2007;116:1449-1457. [PubMed: 17785620]

11. Scirica BM. Ranolazine in patients with coronary artery disease. Expert Opin Pharmacother 2007;8:2149-2157. [PubMed: 17714067]

12. Scirica BM, Morrow DA, Hod H, et al. Effect of Ranolazine, an Antianginal Agent With Novel Electrophysiological Properties, on the Incidence of Arrhythmias in Patients With Non ST-Segment Elevation Acute Coronary Syndrome: Results From the Metabolic Efficiency With Ranolazine for Less Ischemia in Non ST-Elevation Acute Coronary Syndrome Thrombolysis in Myocardial Infarction 36 (MERLIN-TIMI 36) Randomized Controlled Trial. Circulation 2007;116:1647-1652. [PubMed: 17804441]

13. Haissaguerre M, Jais P, Shah DC, et al. Electrophysiological end point for catheter ablation of atrial fibrillation initiated from multiple pulmonary venous foci. Circulation 2000;101:1409-1417. [PubMed: 10736285]

14. Nattel S, Allessie MA, Haissaguerre M. Spotlight on atrial fibrillation-the 'complete arrhythmia'. Cardiovasc Res 2002;54:197-203. [PubMed: 12062326]

15. Nattel S. Combined parasympathetic-sympathetic nerve discharge and pulmonary vein afterdepolarizations: A new unifying concept with basic and clinical relevance. Heart Rhythm 2005;2:632-633. [PubMed: 15922272]

16. Pappone C, Santinelli V, Manguso F, et al. Pulmonary vein denervation enhances long-term benefit after circumferential ablation for paroxysmal atrial fibrillation. Circulation 2004;109:327-334. [PubMed: 14707026]

17. Chen YJ, Chen SA, Chang MS, et al. Arrhythmogenic activity of cardiac muscle in pulmonary veins of the dog: implication for the genesis of atrial fibrillation. Cardiovasc Res 2000;48:265-273. [PubMed: 11054473]

18. Chen YJ, Chen SA. Electrophysiology of pulmonary veins. J Cardiovasc Electrophysiol 2006;17:220224. [PubMed: 16533265]

19. Burashnikov A, Antzelevitch C. Reinduction of atrial fibrillation immediately after termination of the arrhythmia is mediated by late phase 3 early afterdepolarization-induced triggered activity. Circulation 2003;107:2355-2360. [PubMed: 12695296]

20. Undrovinas AI, Belardinelli L, Undrovinas NA, et al. Ranolazine improves abnormal repolarization and contraction in left ventricular myocytes of dogs with heart failure by inhibiting late sodium current. J Cardiovasc Electrophysiol 2006;17:S161-S177.

21. Kirchhof PF, Fabritz CL, Franz MR. Postrepolarization refractoriness versus conduction slowing caused by class I antiarrhythmic drugs: antiarrhythmic and proarrhythmic effects. Circulation 1998;97:2567-2574. [PubMed: 9657478]

22. Costard-Jackle A, Franz MR. Frequency-dependent antiarrhythmic drug effects on postrepolarization refractoriness and ventricular conduction time in canine ventricular myocardium in vivo. J Pharmacol Exp Ther 1989;251:39-46. [PubMed: 2795468] 
23. Lee RJ, Liem LB, Cohen TJ, et al. Relation between repolarization and refractoriness in the human ventricle: cycle length dependence and effect of procainamide. J Am Coll Cardiol 1992;19:614-618. [PubMed: 1538018]

24. Golod DA, Kumar R, Joyner RW. Determinants of action potential initiation in isolated rabbit atrial and ventricular myocytes. Am J Physiol 1998;274:H1902-H1913. [PubMed: 9841518]

25. Belardinelli L, Shryock JC, Fraser H. Inhibition of the late sodium current as a potential cardioprotective principle: effects of the late sodium current inhibitor ranolazine. Heart 2006;92:iv6iv14. [PubMed: 16775092]

26. Song Y, Shryock J, Wagner S, et al. Blocking late sodium current reduces hydrogen peroxide-induced arrhythmogenic activity and contractile dysfunction. J Pharmacol Exp Ther 2006;318:214-222. [PubMed: 16565163]

27. CAST Investigators: Preliminary report: Effect of encainide and flecainide on mortality in a randomized trial of arrhythmia suppression after myocardial infarction. N Engl J Med 1989;321:406412. [PubMed: 2473403]

28. Antzelevitch C, Shimizu W, Yan GX, et al. The M cell: its contribution to the ECG and to normal and abnormal electrical function of the heart. J Cardiovasc Electrophysiol 1999;10:1124-1152. [PubMed: 10466495]

29. Nattel S, Kneller J, Zou R, et al. Mechanisms of termination of atrial fibrillation by Class I antiarrhythmic drugs: evidence from clinical, experimental, and mathematical modeling studies. $\mathrm{J}$ Cardiovasc Electrophysiol 2003;14:S133-S139. [PubMed: 14760915]

30. Chaitman BR. Ranolazine for the treatment of chronic angina and potential use in other cardiovascular conditions. Circulation 2006;113:2462-2472. [PubMed: 16717165]

31. Sicouri S, Timothy KW, Zygmunt AC, et al. Cellular basis for the electrocardiographic and arrhythmic manifestations of Timothy syndrome: effects of ranolazine. Heart Rhythm 2007;4:638-647.

[PubMed: 17467634]

\section{Abbreviations / Acronyms}

ACh, Acetylcholine

$\mathrm{AF}$, atrial fibrillation

$\mathrm{APD}_{50}$, action potential duration measured at $50 \%$ repolarization

$\mathrm{APD}_{85}$, action potential duration measured at $85 \%$ repolarization

BCL, basic cycle length

DADs, delayed afterdepolarizations

EADs, early afterdepolarizations

$\mathrm{I}_{\mathrm{Ca}}$, calcium current

$\mathrm{I}_{\mathrm{K} 1}$, inward rectifier potassium current

$\mathrm{I}_{\mathrm{Kr}}$, rapidly activating delayed rectifier potassium current

$\mathrm{I}_{\mathrm{Ks}}$, slowly activating delayed rectifier potassium current

$\mathrm{I}_{\mathrm{Na}}$, sodium current

$\mathrm{I}_{\text {to }}$, transient outward current

late $\mathrm{I}_{\mathrm{Na}}$, late sodium current

$\mathrm{PV}$, pulmonary vein

$\mathrm{V}_{\max }$, maximal rate of rise of action potential upstroke 


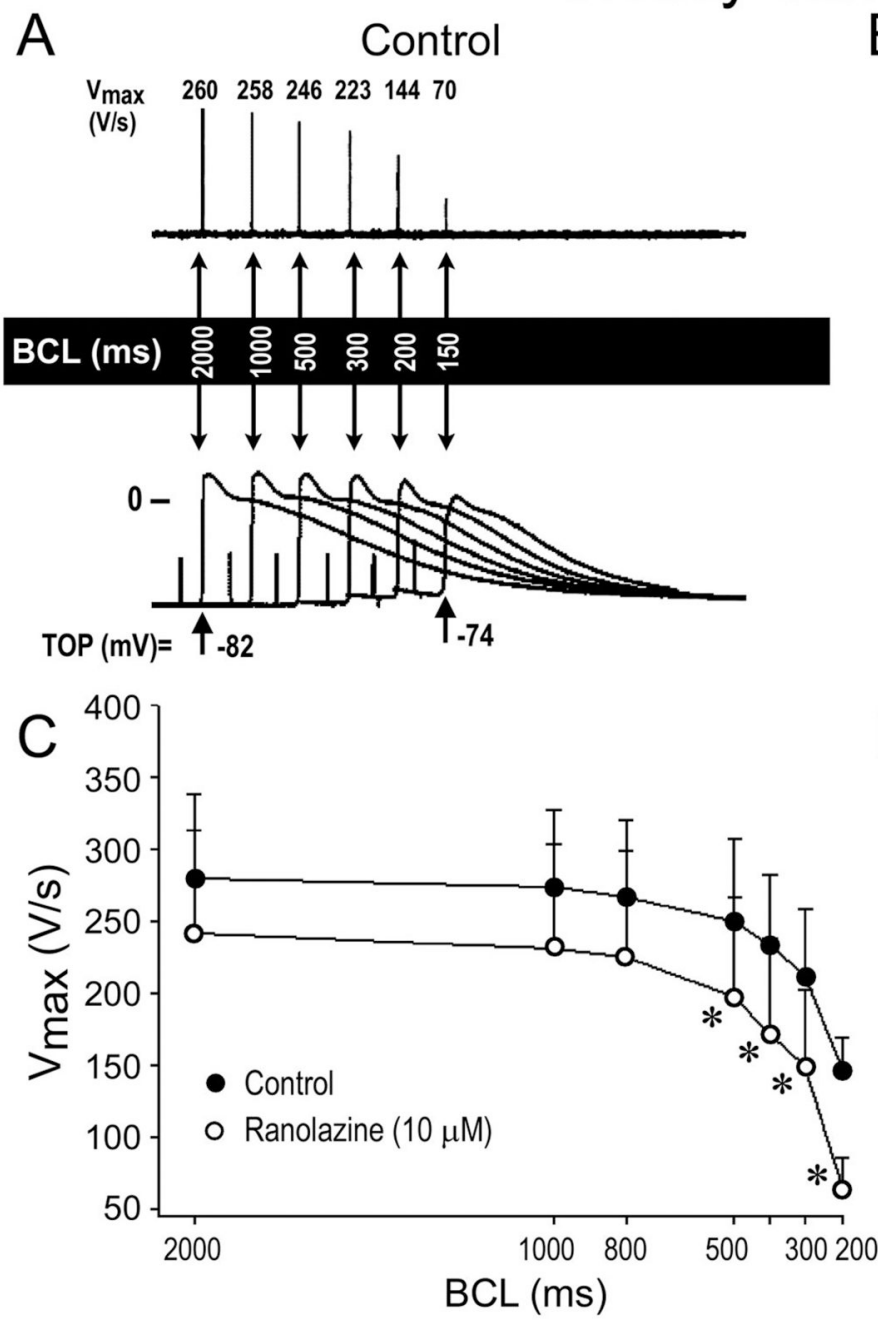

\section{Steady-state Conditions}
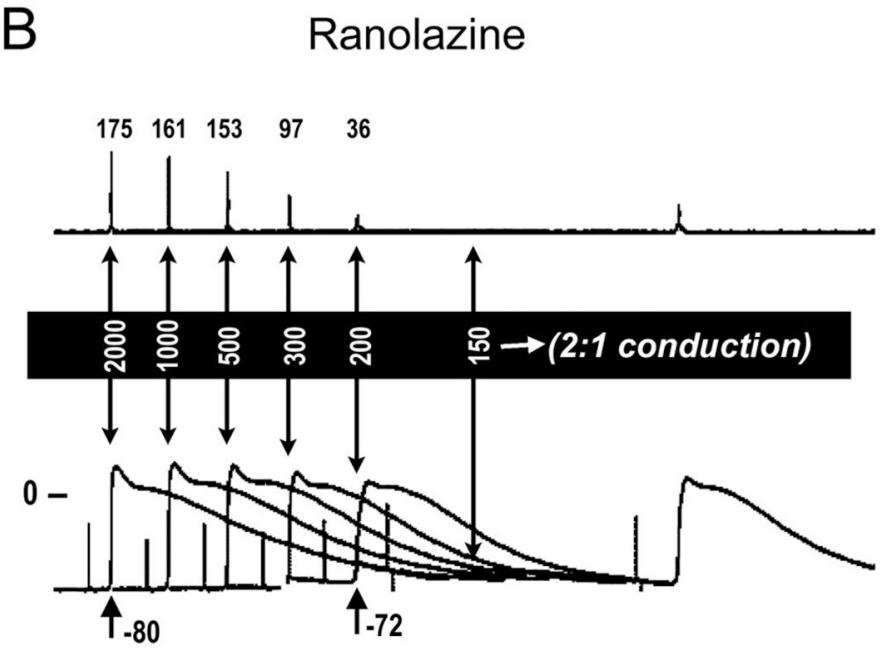

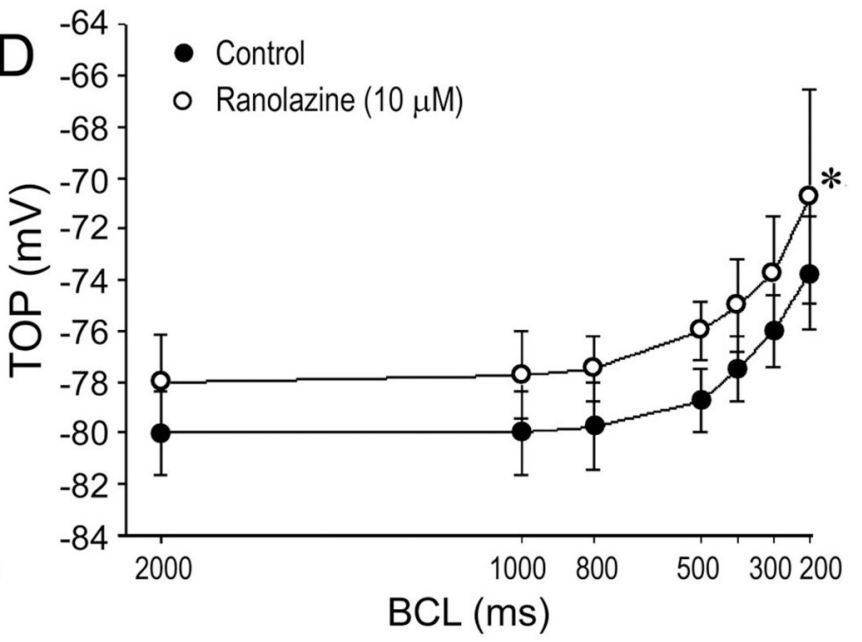

Figure 1.

Rate-dependent effects of ranolazine on maximum rate of rise of action potential upstroke $\left(\mathrm{V}_{\text {max }}\right)$ and take-off potential (TOP) of action potentials recorded from PV sleeve preparations $(n=4)$. A and B: Representative examples of action potentials recorded at various basic cycle lengths (BCLs) in the absence (control, panel A) and presence of $10 \mu \mathrm{M}$ ranolazine (panel B). $\mathrm{C}$ and D: Summary of the rate-dependent effects of ranolazine on $\mathrm{V}_{\max }$ and TOP. Ranolazine induced a marked decrease in $\mathrm{V}_{\max }$ and a small (2 to $5 \mathrm{mV}$ ) depolarization of TOP. Data are expressed in mean $\pm \mathrm{SD}$, $* \mathrm{p}<0.05$ ranolazine vs. control. 


\section{Abrupt Change in Basic Cycle Length (BCL)}

Control
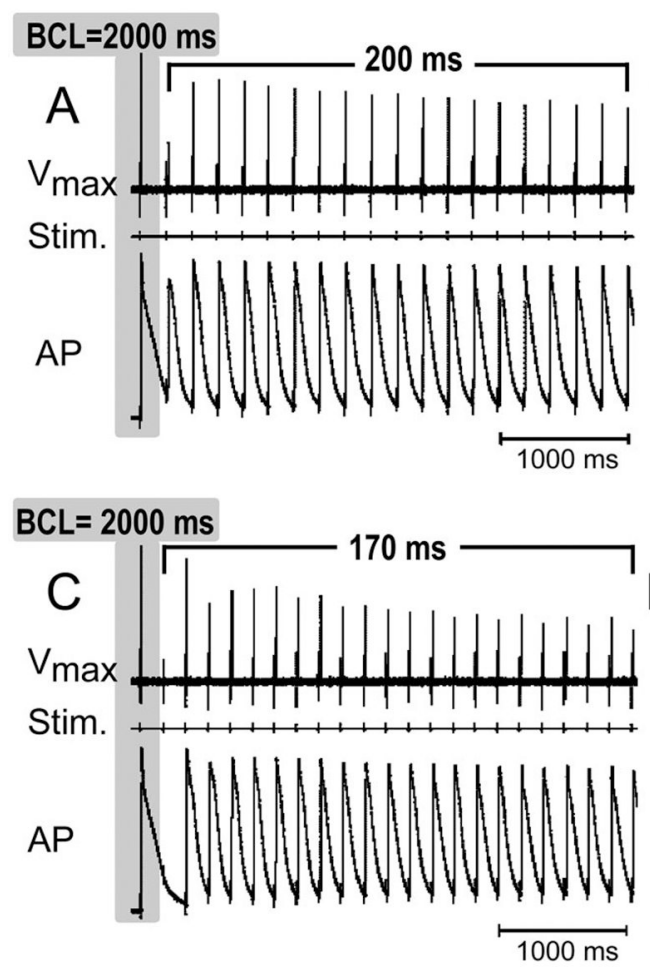

Ranolazine

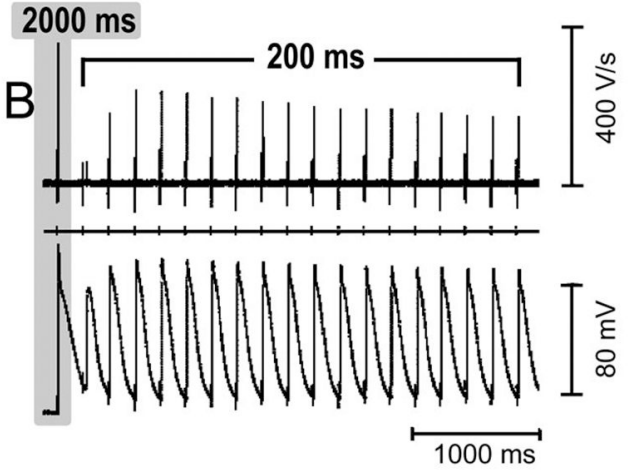

$2000 \mathrm{~ms}$
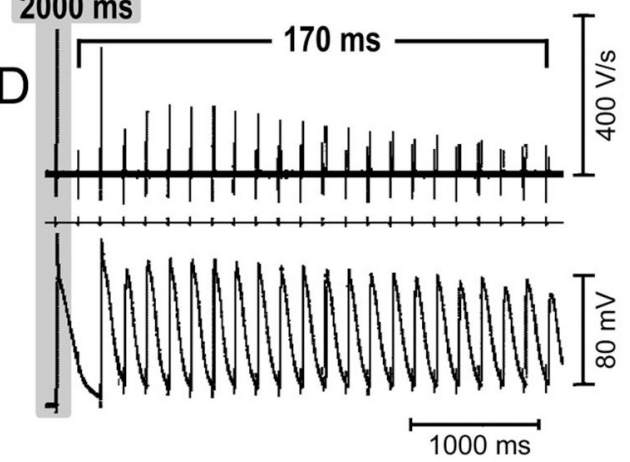

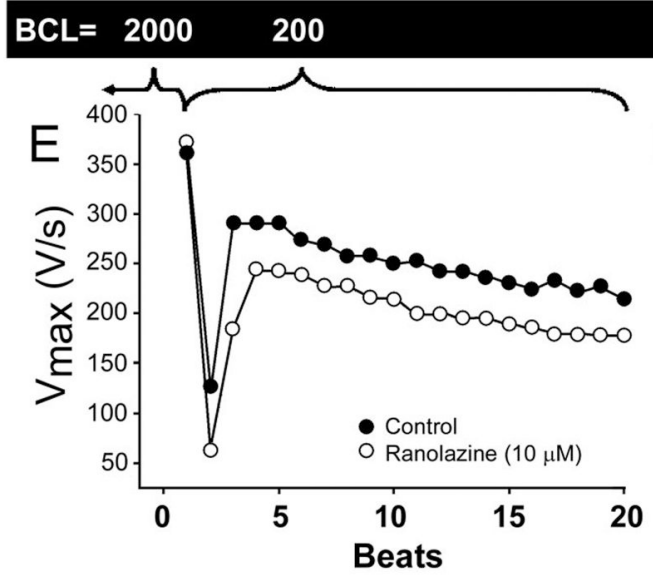

\section{$2000 \quad 170 \mathrm{~ms}$}

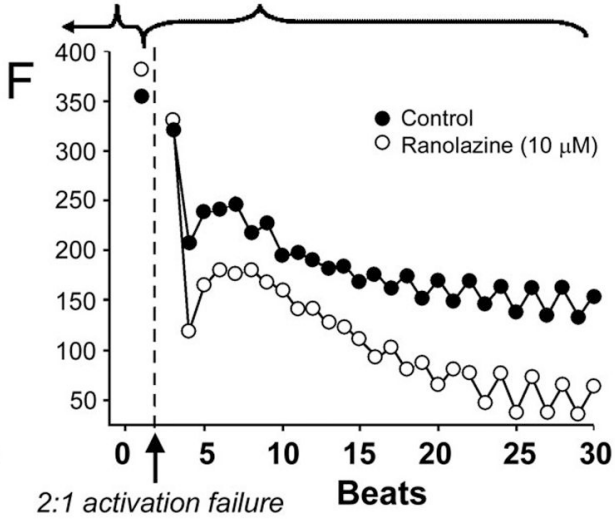

Figure 2.

Effects of ranolazine $(10 \mu \mathrm{M})$ on maximum upstroke velocity of the action potential $\left(\mathrm{V}_{\max }\right)$ following an abrupt change in basic cycle length (BCL) in a PV sleeve preparation. Upper panel: Recordings of APs and $\mathrm{V}_{\max }$ following a change in BCL from 2000 to $200 \mathrm{~ms}$ (A, control; B, Ranolazine) and from 2000 to $170 \mathrm{~ms}$ (C, control; D, Ranolazine). Lower panel: Plot of beat to beat changes in $\mathrm{V}_{\max }$ (E, control; $\mathrm{F}$, Ranolazine). 


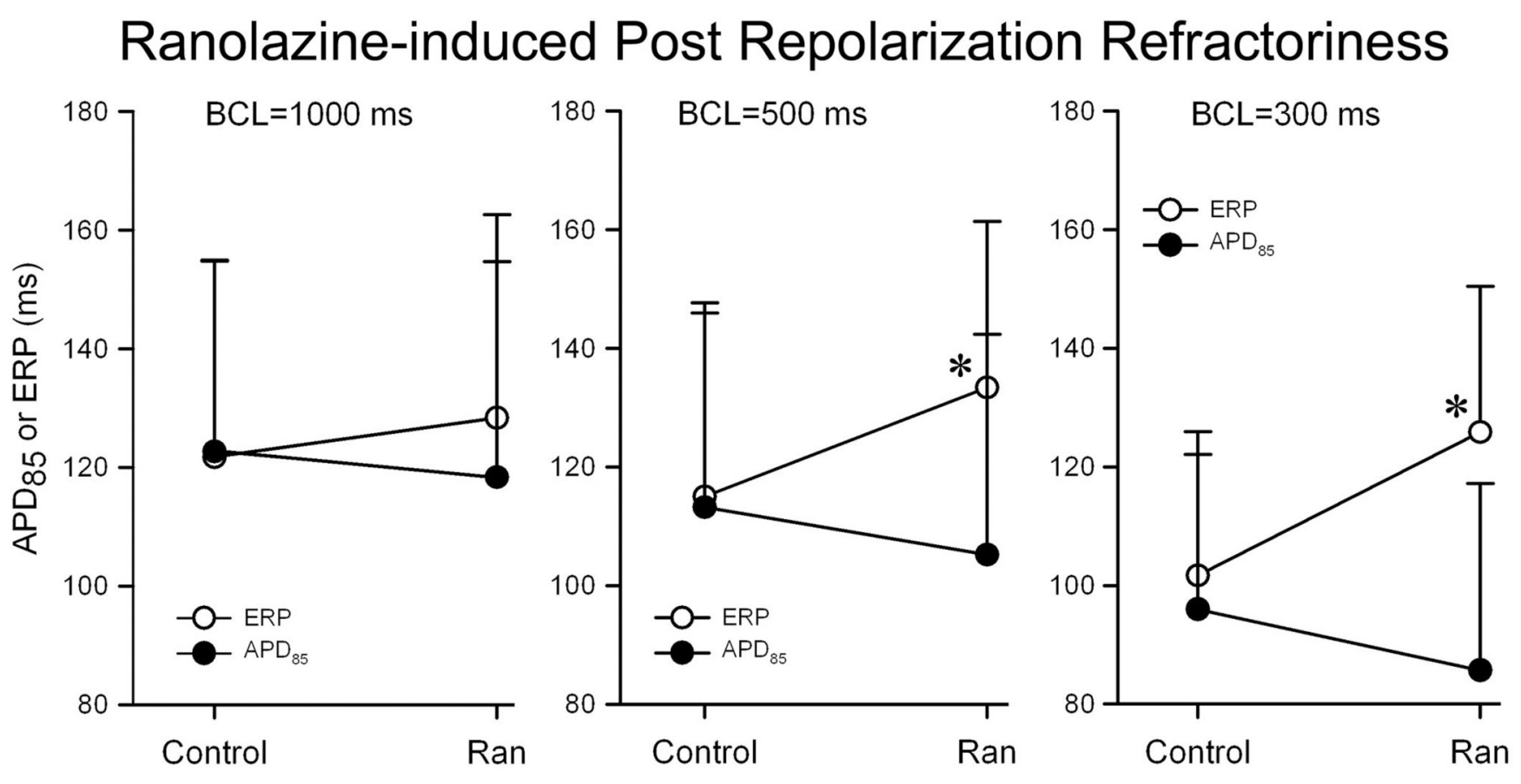

Figure 3.

Ranolazine $(10 \mu \mathrm{M})$-induced postrepolarization refractoriness in PV sleeve preparations $(\mathrm{n}=$ 6). Ranolazine induced a rate-dependent decrease in $\mathrm{APD}_{85}$, but an increase in ERP leading due to development of PRR (the difference between ERP and $\mathrm{APD}_{85}$ ); $n=6$. Data are expressed in mean $+\mathrm{SD} .{ }^{*} \mathrm{p}<0.05 ;$ ERP vs $\mathrm{APD}_{85}$. 


\section{Ranolazine-induced Conduction Block in PV Sleeve}
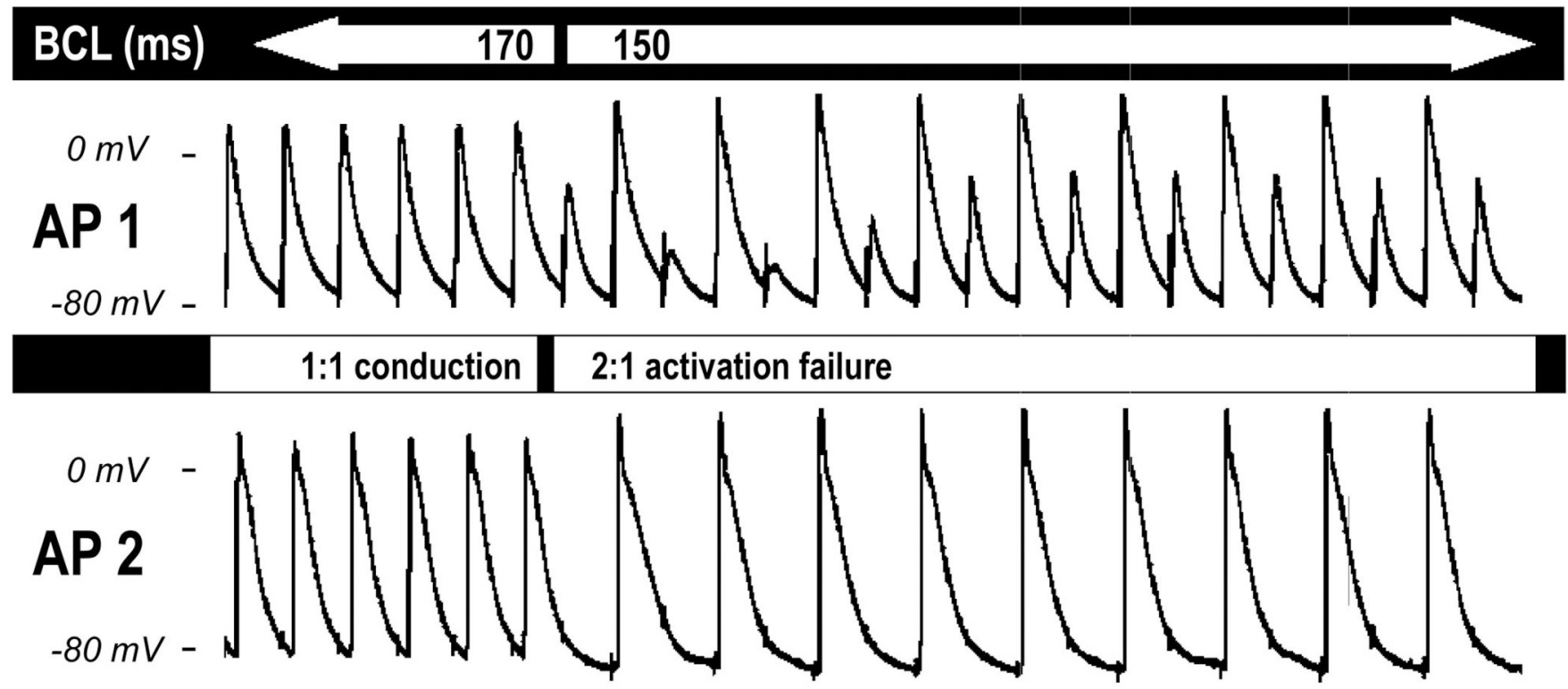

Figure 4.

Ranolazine $(10 \mu \mathrm{M})$-induced impulse conduction block in a PV sleeve preparation. Simultaneous recordings of two actions potentials (AP1 and AP2) along a PV sleeve preparation (interelectrode distance $=16 \mathrm{~mm}$ ). The $1: 1$ conduction observed at basic cycle length (BCL) of $170 \mathrm{~ms}$ (first 6 beats) deteriorates to $2: 1$ conduction at a BCL of $150 \mathrm{~ms}$. 


\section{Ranolazine Suppresses Isoproterenol-induced DADs and Triggered Activity Isoproterenol $(1 \mu \mathrm{M})$}

\begin{tabular}{|c|c|c|c|c|c}
\hline BCL (ms) & 200 & 150 & 120 & 120
\end{tabular}

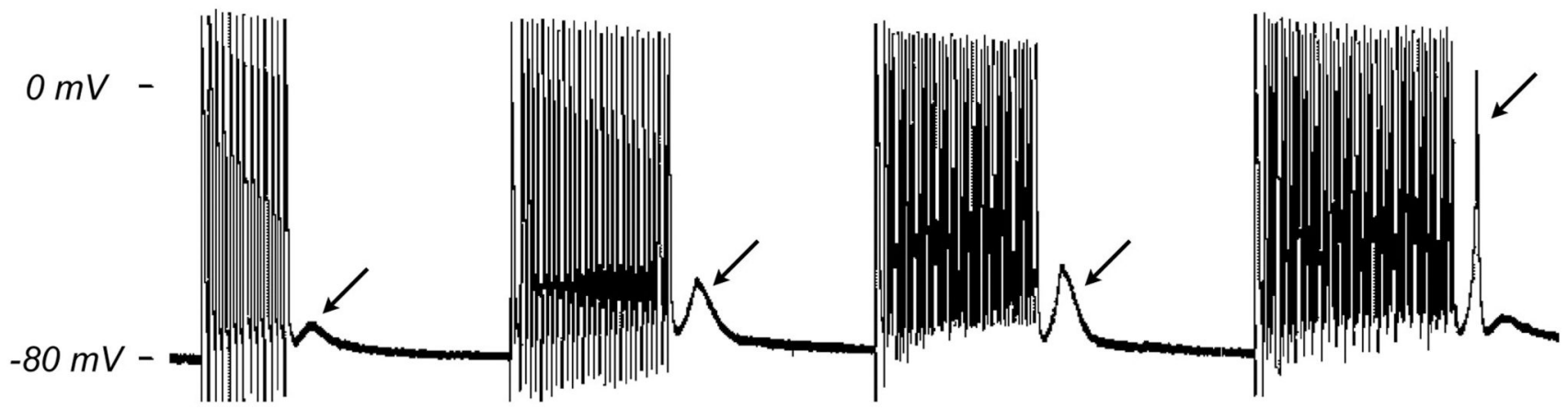

+ Ranolazine $(10 \mu \mathrm{M})$

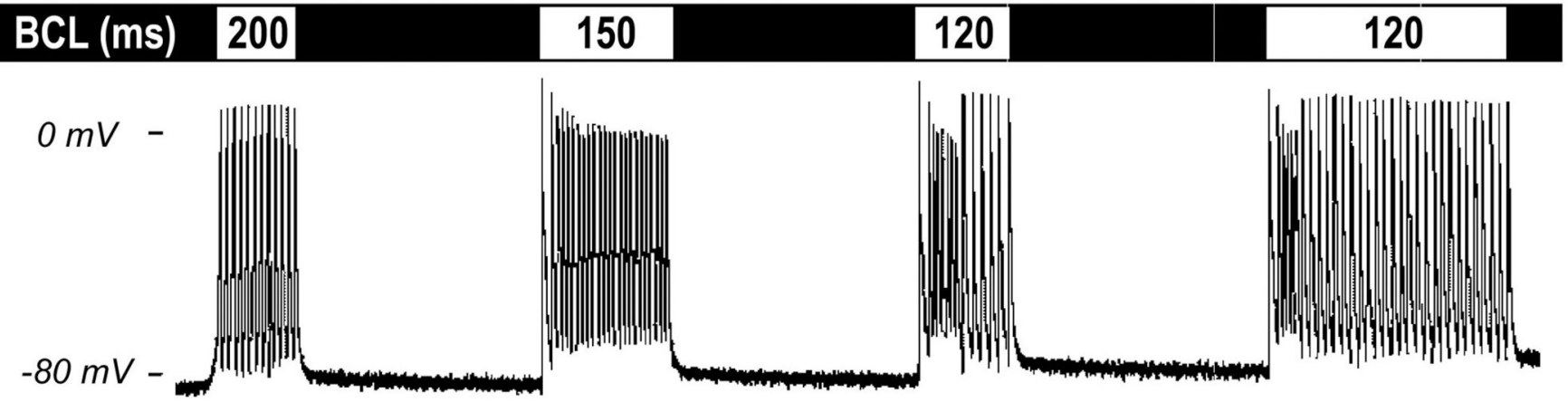

Figure 5.

Ranolazine suppresses delayed afterdepolarizations (DADs) and triggered activity (TA) induced by isoproterenol in a PV sleeve preparation. Upper panel: effect of isoproterenol (1 $\mu \mathrm{M})$. DAD activity is apparent following a train of 20 beats at basic cycle length (BCL) of 200 $\mathrm{ms}$, and increases in amplitude as BCL is reduced to 150 and $120 \mathrm{~ms}$. The DAD reaches threshold as the train was extended to 35 beats, giving rise to a triggered beat (arrow) followed by a small DAD. Lower panel: ranolazine abolished the DAD and DAD-induced TA. 


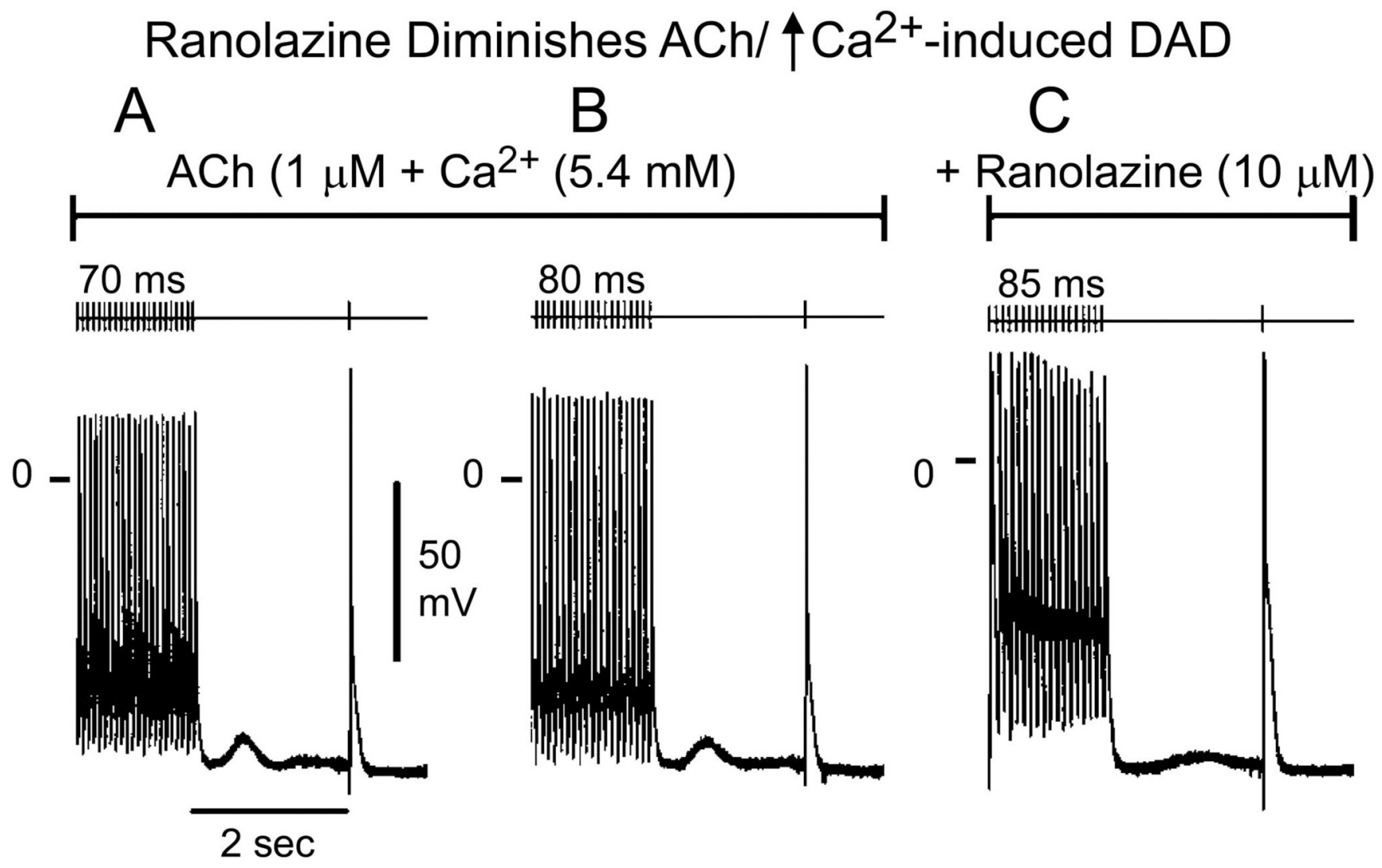

Figure 6.

Ranolazine reduces the amplitude of $\mathrm{ACh}$ and high calcium $\left(\left[\mathrm{Ca}^{2+}\right]_{\mathrm{o}}=5.4 \mathrm{mM}\right)$-induced delayed afterdepolarization (DAD) in a PV sleeve preparation. $\mathbf{A}$ and $\mathbf{B}$ : $\mathrm{ACh} / \mathrm{high}$ calcium induces DAD activity at basic cycle length (BCL) of 70 and $80 \mathrm{~ms}$, respectively. C: ranolazine markedly reduced DAD amplitude at a BCL of $85 \mathrm{~ms}$ (fastest rate permitting 1:1 activation). 


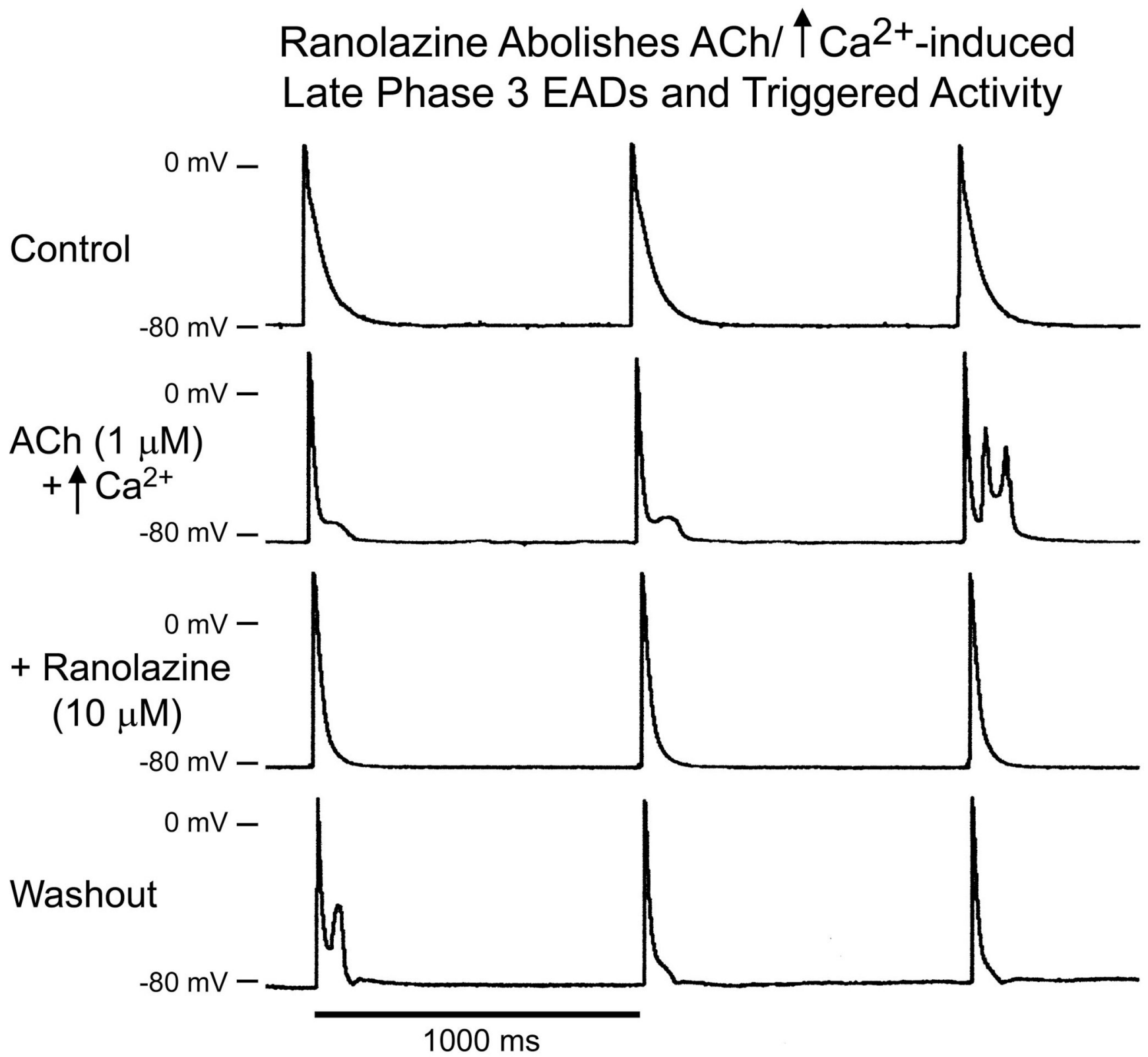

Figure 7.

Ranolazine abolishes late phase 3 EADs and triggered activity (TA) induced by ACh and high calcium $\left(\left[\mathrm{Ca}^{2+}\right]_{\mathrm{O}}=5.4 \mathrm{mM}\right)$ in a PV sleeve preparation. Basic cycle length $(\mathrm{BCL})=1000 \mathrm{~ms}$. A. control. B. ACh/high calcium induced late phase 3 EADs (first 2 beats) and late-phase 3 EAD-induced triggered activity (TA) (third beat). C. Ranolazine $(10 \mu \mathrm{M})$ abolished late phase 3 EADs and TA. D. Upon washout of ranolazine (30 minutes), late phase 3 EADs and TA reappear. 


\section{Ranolazine suppresses DADs}

Table 1

Effect of ranolazine on $\mathrm{ACh}$ and high calcium $\left(\left[\mathrm{Ca}^{2+}\right]_{\mathrm{o}}=5.4 \mathrm{mM}\right)$-induced delayed afterdepolarizations (DADs). Summarized are the maximum amplitudes and coupling intervals of the DADs and the concentrations of ranolazine needed to suppress the DADs by $\geq 90 \%$. DADs were elicited by stimulation trains of 20 beats at a BCL of 70 to 200 $\mathrm{ms}$

\begin{tabular}{|c|c|c|c|}
\hline Exp \# & Max DAD Amplitude (mV) & Coupling Interval of DAD (ms) & [Ranolazine] to Suppress DAD ( $\mathbf{\mu M})$ \\
\hline 1 & 7.2 & 630 & 10 \\
\hline 2 & 7.5 & 610 & 20 \\
\hline 3 & 5.3 & 380 & 10 \\
\hline 4 & 6.4 & 427 & 10 \\
\hline 5 & 5.7 & 448 & 20 \\
\hline
\end{tabular}

